\title{
pÿTrajectories of Teachers Perceived Curriculum Coherence in the Context of Finnish Core Curriculum Reform
}

\section{Sullanmaa, Jenni}

2019

pÿSullanmaa , J , Pyhältö , K , Soini , T \& Pietarinen , J 2019 , ' Trajectories of Teachers

Perceived Curriculum Coherence in the Context of Finnish Core Curriculum Reform ' ,

Curriculum and Teaching , vol. 34 , no. 2 , pp. 27-49 . https://doi.org/10.7459/ct/34.2.03

http://hdl.handle.net/10138/313841

https://doi.org/10.7459/ct/34.2.03

unspecified

acceptedVersion

Downloaded from Helda, University of Helsinki institutional repository.

This is an electronic reprint of the original article.

This reprint may differ from the original in pagination and typographic detail.

Please cite the original version. 


\title{
Trajectories of teachers' perceived curriculum coherence in the context of Finnish core curriculum reform
}

\author{
MA, Jenni Sullanmaa, corresponding author \\ Faculty of Educational Sciences, University of Helsinki \\ Prof. Kirsi Pyhältö \\ Faculty of Educational Sciences, University of Oulu \\ Professor, Center for University Teaching and Learning, Faculty of Educational Sciences, University of \\ Helsinki \\ Extraordinary Professor, University of Stellenbosch, South-Africa. \\ Dr., Research Director, Tiina Soini \\ School of Education, University of Tampere \\ School of Applied Educational Science and Teacher Education, University of Eastern Finland \\ Prof. Janne Pietarinen \\ School of Applied Educational Science and Teacher Education, University of Eastern Finland
}

\begin{abstract}
Teachers play a key role in transforming the national curriculum reform into classroom practice. This study explored individual variation in Finnish teachers' $(N$ $=901$ ) perceptions of curriculum coherence during a one-year follow-up during the early stages of its implementation in schools. Latent profile analysis revealed five distinctive profiles. The development of perceived curriculum coherence over the two measurements and the perceived school-level impact of the reform differed between the profiles. The results imply that teachers may need various kinds of support to arrive at a coherent understanding of the curriculum over the process of its development and implementation.
\end{abstract}

Keywords: Curriculum coherence, educational change, comprehensive school, latent profile analysis

\section{Funding}

This work was supported by the Finnish Ministry of Education and Culture [grant number 6600567]; and the Academy of Finland [grant number 295022]. 


\section{Introduction}

Curriculum reform is a complex and dynamic process entailing adaptation and (re-)definition both within and between the different levels of the educational system (Darling-Hammond, 1998; Spillane, Reiser, \& Reimer, 2002). It calls for a sustained collective effort involving different stakeholders ranging from administrators to educational practitioners in interpreting and adapting the reform (Fullan, 2007; Gawlik, 2015). Teachers play a key role in transforming and enacting the new curriculum in the classroom (Cohen \& Hill, 2000; Day, Sammons, Stobart, Kington, \& Gu, 2007). This is particularly true in Finland, where the educational system emphasizes the autonomy of schools and teachers, relying heavily on the commitment of teachers to school development, actively adopting non-standardized, largescale national curriculum reform and modifying it according to local needs. The national core curriculum sets the general goals, core contents, and principles for basic education. It is also a tool enabling schools and teachers to develop their pedagogical praxis (Vitikka, Krokfors, \& Rikabi, 2016). Teachers' perceptions of the curriculum contribute to the ways in which it is realized in the everyday life of schools. Changes in teachers' understandings take time and are shaped in interaction with classroom practice (Coburn, 2004; Spillane et al., 2002). By enacting and experimenting with the curriculum in everyday school practice, teachers develop their understanding of the curriculum.

Accordingly, the impact of the curriculum reform on schools is dependent on the teachers' interpretations of the curriculum and their beliefs about its potential effects (Cohen \& Hill, 2000; Fullan, 2007; Penuel, Fishman, Gallagher, Korbak, \& Prado-Lopez, 2008; Priestley, Minty, \& Eager, 2014). In particular, it is suggested that teachers' perceptions of curriculum coherence contribute to their understanding of the curriculum and through this contribute to school development and coherence in practice (see Allen \& Penuel, 2015; Fullan, 1996; Newmann, Smith, Allensworth, \& Bryk, 2001; Russell \& Bray, 2013; Penuel et al., 2008; Tan \& Nashon, 2015). Teachers' perceptions of school-level coherence have also been shown to relate to pupil achievement (Newmann et al., 2001). Prior research on curriculum coherence has mainly focused on alignment among objectives or standards, content, instructional activities, and assessment, as well as on the progression and sequencing of content within learning units and grades (e.g. Fortus, Sutherland Adams, Krajcik, \& Reiser, 2015; Schmidt, Wang, \& McKnight, 2005). Less is known about the extent to which educational practitioners perceive the national core curriculum document to provide a consistent, integrative and aligned framework for the development of school practice. We recently showed that district-level stakeholders' perceptions of curriculum coherence were related to the perceived potential school-level impact of the reform, i.e. how the reform work was perceived to engage teachers in working on developing the school and to maintain active development work on the school level (Sullanmaa et al., 2019a). Yet, as far as we know, no prior studies have explored how teachers' perceptions of curriculum coherence, specifically in terms of the consistency of the intended direction, integrative approach to teaching and 
learning, and alignment between objectives, content and assessment, evolve during the reform process. This study contributes to the gap in the literature in exploring individual variation among Finnish teachers' perceptions of curriculum coherence, and how these perceptions develop during the first year of curriculum implementation in schools. We also examined the association between the curriculum coherence profiles and the perceived impact of the reform on school-level development work.

\subsection{Finnish core curriculum reform}

The Finnish core curriculum is a national steering document that provides the framework for local curricula. The Finnish National Agency for Education (previously the Finnish National Board of Education [FNBE]), an independent governmental agency, is responsible for orchestrating construction of the national core curriculum in line with the juridical framework of the Basic Education Act. The core curriculum includes the mission and values of basic education, the objectives and core content of school subjects, a general framework for the development of the school culture and teaching practices, and principles of pupil assessment (FNBE, 2014). Its construction is an interactive process involving a network of different stakeholders, including administrators and representatives from universities, education providers, schools, and associations (Vitikka et al., 2016). The new core curriculum, which was published in 2014, emphasizes sustainability, the uniqueness of each pupil, and the role of the pupil as an active learner (FNBE, 2014). For the first time, it also includes transversal competences to be developed in all school subjects (Vitikka et al., 2016). Collaborative and active learning, versatile working methods, and integrative instruction are encouraged (FNBE, 2014).

Local education providers are responsible for constructing the district- or municipality-level curriculum based on the national core curriculum. They have extensive autonomy both in orchestrating the development work and in developing the local curriculum based on the national core curriculum (Vitikka et al., 2016). Curriculum development is orchestrated on the district level by coordinating groups including educational practitioners from the schools as well as municipal actors (Pyhältö, Pietarinen, \& Soini, 2018; Vitikka et al., 2016). The implementation of the new curriculum was launched in the fall of 2016 in primary schools, and continues in phases during 2017-2019 in lower-secondary schools. The curriculum reform process is intended to involve local stakeholders and school staff in the local curriculum development work to foster ownership of the change in the local contexts (Mølstad, 2015; Vitikka et al., 2016). Schools and teachers may vary in terms of the school culture and instructional practices, depending on how they interpret and understand the core curriculum as a tool for developing local school practice. Finnish teachers have the pedagogical autonomy to decide on the teaching methods and materials they use, and pupil assessment is conducted by the teachers according to the curriculum (see Kumpulainen \& Lankinen, 2016). Thus, the educational system relies heavily on the proficiency of teachers (see Sahlberg, 2015). 


\subsection{Curriculum coherence}

Curriculum coherence in terms of connectedness, integration, and continuity is proposed to constitute a sustainable basis for curriculum development (Beane, 1995; Geraedts, Boersma, $\&$ Eijkelhof, 2006). Curriculum coherence consists of three complementary components: consistency of the intended direction, an integrative approach to teaching and learning, and alignment between objectives, content and assessment (Sullanmaa, Pyhältö, Pietarinen, \& Soini, 2019a). Consistency of the intended direction refers to providing a consistent direction for the school practice in terms of clarifying and supporting the work of schools and teachers, summing up the most important goals, and supporting the teaching of essential material (Sullanmaa et al., 2019a). It implies facilitating shared goals in the educational system and a shared vision of what schools should be like, which are crucial preconditions for large-scale reform (Darling-Hammond, 1998; Fullan, 2007; Newmann et al., 2001; Smith \& O’Day, 1991). Active sense-making and "crafting coherence" in the face of overlapping policy demands are of particular importance to the stakeholders and practitioners involved in school reforms (Honig \& Hatch, 2004; Russell \& Bray, 2013). Moreover, it is suggested that a clear and holistic understanding of the curriculum contributes to its school-level enactment (Priestley et al., 2014). In turn, perceiving the reform message, the curriculum, or the supporting materials as unclear, insignificant or contradictory is likely to increase uncertainty among teachers (Boesen, Helenius, Bergqvist, Bergqvist, Lithner, Palm, \& Palmberg, 2013; Priestley et al., 2014; Smith \& Southerland, 2007). Hence, consistency in the curriculum's goals and the roles of teachers and schools is a crucial aspect of curriculum coherence. Collaboration and strong collegiality among the teacher community in developing a shared and coherent vision of the reform and its aims on the school level are also essential to foster teacher ownership and agency with regard to the implementation (see Geijsel, Sleegers, van den Berg \& Kelchtermans, 2001; Pyhältö, Pietarinen, \& Soini 2012; Robinson, 2012). Hence, curriculum reforms require a consistent direction that is agreed upon among educational practitioners (Fullan, 2007; Smith \& O'Day, 1991). At the same time as providing a coherent basis on which to develop local practices, the consistency should also allow for variation so that contextual needs can be taken into account (Pietarinen, Pyhältö, \& Soini, 2017; Vitikka et al., 2016).

The second component of curriculum coherence, an integrative approach to teaching and learning, entails harmonizing teaching and encouraging teachers to use activating teaching methods and assessment that supports learning (Sullanmaa et al., 2019a). Creating a coherent framework for the development of teaching and learning is yet another precondition for successful reform (Newmann et al., 2001; Smith \& O’Day, 1991). Active teacher involvement in curriculum reform is suggested to call for both developing a new understanding within the teacher community and sufficient agreement with the reform's principles and the values of teaching and learning (e.g. Coburn, 2004; Darling-Hammond \& McLaughlin, 1995). Previous research has shown that a lack of understanding about how 
teachers should change their teaching practices in line with the curriculum reform may relate to uncertainty or superficial implementation (Fullan, 2007; Smith \& Southerland, 2007). As an element of curriculum coherence, an integrative approach to teaching and learning is related to a holistic approach to teaching, connecting and applying learning to a larger purpose, and integration across subjects (see Beane, 1995; Geraedts et al., 2006; Smith \& O’Day, 1991). However, integrative instruction and facilitating active and engaging learning require new strategies and collaboration between teachers (Darling-Hammond, 1998; Drake $\&$ Miller, 2001; Geraedts et al., 2006). The integrative approach should be supported collectively by the school community and requires support for teachers' commitment and capacity-building.

The third component of curriculum coherence, alignment between objectives, content and assessment, refers to the connectedness between the objectives, content, instruction, and assessment (Squires, 2009; Sullanmaa et al., 2019a; Webb, 1997). It is reflected in the extent to which the different elements of the curriculum cohere, build on each other across subjects and grades, and acknowledge the pupils' age range while aiming at higher levels of understanding and achievement (Schmidt et al., 2005; Webb, 1997). Building alignment is suggested as a mean to reduce fragmentation and contradiction both within the curriculum and between educational systems and policy demands (Russell \& Bray, 2013; Webb, 1997). There is a significant body of research on the alignment of standards, instruction, and tests, which has been shown to enhance pupil achievement (see Martone \& Sireci, 2009; Squires, 2009). Prior research has focused on comparing components or policies on the level of the educational system, and evaluating how well they are aligned (see Martone \& Sireci, 2009). It has also been proposed that alignment may enhance teachers' understanding of the curriculum, although thus far teachers' perceptions of curriculum alignment have been studied less. Alignment alone is not sufficient to guarantee coherent perceptions of the curriculum, however (see Penuel et al., 2008). Coherence also incorporates the quality of the aligned elements, including the extent to which the curriculum supports and clarifies the work of teachers and schools. This is considered by complementing alignment with the other elements of curriculum coherence, i.e. integrative approach to teaching and learning, and consistency of the intended direction.

Collective efforts to interpret and discuss the curriculum may increase teachers' sense of coherence and ownership over the curriculum (see Tan \& Nashon, 2015). According to our recent research findings, curriculum coherence perceived by district-level stakeholders involved in the development of local curricula contributes to their perceptions of the reform's impact on school-level development work, in terms of committing teachers to the development work and supporting development of locally functional solutions (Sullanmaa et al., 2019a). We also found that district-level stakeholders responsible for the construction of local curricula were more likely to perceive the consistency of the intended direction of the core curriculum and the school impact of the reform lower than state-level stakeholders responsible for constructing the core curriculum (Sullanmaa et al., 2019b). Thus, teachers' 
perceptions of curriculum coherence may also vary depending on how the curriculum development process has been organized and supported on the district and school levels, and on how individual educational practitioners have constructed shared and coherent understandings of the change.

\subsection{School impact}

The extent to which changes occur in schools is dependent on the teachers' interpretations of the curriculum reform and changes in their thinking and practice (Fullan, 2007). Teachers build their understanding of the reforms based on their professional beliefs and experiences (Coburn, 2004; Fernandez, Ritchie, \& Barker, 2008; Spillane et al., 2002). Further, the understanding they construct about the curriculum reform influences the ways in which it is realized in classroom practice (Cohen \& Hill, 2000; Gawlik, 2015; März \& Kelchtermans, 2013).

Curriculum reform aimed at sustainable school development should be based on the core practices of teaching and learning (e.g. Coburn, 2003; Smith \& O'Day, 1991). Teachers, for instance, need to perceive the change as meaningful for their work, for instance resolving problems they have faced in school-level practices (Fullan, 2007; Southerland, Sowell, Blanchard, \& Granger, 2011). At best, reform promotes school development and the commitment of teachers to it by enabling them to cope better with the diverse and changing needs of school reality (e.g. Drake \& Miller, 2001; März \& Kelchtermans, 2013). A reform policy that conflicts with the teachers' professional identity or fails to communicate its goals, underlying principles and benefits to the local level may hinder active agency among teachers in the reform context (Ketelaar, Beijaard, Boshuizen, \& Den Brok, 2012; Lasky, 2005; Ng, 2009). Thus, teachers' understandings of the curriculum reform, its underlying principles, and intended effects in schools are crucial for the reform to take root (Fullan, 2007; Spillane et al., 2002).

The curriculum reform and the way it is interpreted in light of the national core curriculum document, as well as how it is organized and supported on different levels of the school system, may promote or inhibit teachers' engagement in the reform (Gawlik, 2015; Geijsel et al., 2001; Ramberg, 2014; Spillane et al., 2002; Waugh \& Godfrey, 1993), and thereby influence the local curriculum enactment and impact of the reform in schools. It has been shown, for instance, that perceived congruence, cost-benefit balance, practicality of the new curriculum, and support contribute to teacher commitment to developing classroom practices, which further reflect their perceptions of the reform's impact (Donnell \& Gettinger, 2015; Lee, 2000; März \& Kelchtermans, 2013; Waugh \& Godfrey, 1993; Yin, Lee, \& Jin, 2011). Moreover, teachers' perceptions of the new curriculum may evolve as they gain more experience of enacting and transforming it in classroom practice. They may, for instance, grow to believe in a reform's importance during implementation, regardless of an initially low readiness to change (Bliss \& Wanless, 2018). In the course of time, teachers may use a variety of strategies, such as comparing the new core curriculum with their existing beliefs 
and previous school development initiatives, and analysing the challenges, possibilities and changes that the new core curriculum obligates the schools and teachers to commit to, in order to translate the ideas of the national core curriculum into the pedagogical practices (Coburn, 2004; Spillane et al., 2002; Pyhältö et al., 2018). Teachers also transform their professional knowledge by clarifying the consequences of the reform in their everyday work and by reflecting on the success of their implemented developmental actions (e.g. Coburn, 2004; Pyhältö et al., 2018). The implication is that facilitating and supporting active sensemaking among teachers might provide a key to curriculum reform's impact on everyday pedagogical practices in schools.

\section{Methods}

\subsection{Aim}

The aim of this study was to examine the trajectories of teachers' perceptions of curriculum coherence over a one-year follow-up in the context of Finnish core curriculum reform. Since previous studies have found individual variation in teachers' interpretations and perceptions of educational change, we used a person-centered approach to explore individual variation among teachers. The aim was to detect homogenous subgroups of teachers in terms of their perceptions of the three core components of curriculum coherence and their development over time. Previous studies have also shown that teachers' understanding and interpretation of the curriculum reform affects the development of their classroom practices and the enactment of the curriculum (e.g. Fernandez et al., 2008; Ketelaar et al., 2012; März \& Kelchtermans, 2013). Hence, we expect the curriculum coherence profiles to differ in terms of the perceived impact of the reform on school development, i.e. how the reform work is perceived to maintain active development on the school level, and teacher commitment to it.

The following hypotheses were tested:

H1. Individual profiles of perceived curriculum coherence, including consistency of the intended direction; integrative approach to teaching and learning; and alignment between objectives, content, and assessment, measured at two time points, can be detected among teachers.

$H 2$. The curriculum coherence profiles differ in terms of the perceived school impact of the reform (Sullanmaa et al., 2019a).

\subsection{Sample}

The participants were comprehensive school teachers from 73 case schools in 6 case districts around Finland. A total of 1556 teachers responded at Time 1 (2016), and 1585 at Time 2 (2017), and the response rate ranged from 79.2 to 81.2 percent. The participants of this study 
comprise the 901 teachers who responded at both time points, representing 58 percent of the total sample at $\mathrm{T} 1$. Of these teachers half $(50 \% ; \mathrm{n}=452)$ taught in primary schools (grades $1-6), 15$ percent $(\mathrm{n}=137)$ in lower-secondary schools (grades $7-9)$, and about a third (35\%; $\mathrm{n}=312$ ) in combined primary and lower-secondary schools (grades 1-9) at T1. The participants also included school leaders such as principals and vice principals $(11 \% ; \mathrm{n}=97)$, most of whom also taught in their schools. Most of the participants were female $(75 \%, \mathrm{n}=$ $676)$, men being in the minority $(25 \%, \mathrm{n}=224)$. The average teaching experience in the sample was 16 years at $\mathrm{T} 1(\mathrm{SD}=9.2 ; \mathrm{min} / \mathrm{max}=0 / 40)$.

\subsection{Instruments}

The data were collected at two time points: the first measurement was in the fall of 2016, when the implementation of the new curriculum started in primary schools, and the second was in the fall of 2017 when the phased implementation extended to grade 7 of lowersecondary school. The participants completed the Curriculum Reform Inventory (Pietarinen et al., 2017), which includes curriculum coherence and school impact scales. The curriculum coherence scale consists of three complementary components (Sullanmaa et al., 2019a): 1) Consistency of the intended direction (6 items); 2) an integrative approach to teaching and learning (4 items); and 3) alignment between objectives, content and assessment ( 7 items ${ }^{1}$ ). The school impact scale measures the meaning and significance of the curriculum reform process on the school level development work (6 items). It entails supporting of sustainable development in schools and directing the development work towards locally functional solutions. The full scales are shown in Appendix 1.

All the items were rated on a seven-point Likert-scale $(1=$ fully disagree; $7=$ fully agree). The percentage of missing values per item varied from 0 to 2.9 and the data were missing completely at random (Little's MCAR test: $\left.x^{2}(3208)=3265.01 ; p=.24\right)$. The structural validity of the scales was first examined with confirmatory factor analysis, which showed that the three-factor measurement model of curriculum coherence and the one-factor model of school impact fitted the data sufficiently well at both time points (see also Sullanmaa et al., 2019a).

Moreover, due to the possible nested structure of the data with teachers within schools, the intra-class correlation coefficient (ICC), which describes the proportion of variance in the curriculum coherence and school impact measurements between the schools, was initially tested (see e.g. Snijders \& Bosker, 2012). In addition to the ICC, the design effect (deff), which approximates the effect of the clustered design and between-group variance and is weighted by the average cluster size was analysed (cut-off criteria deff $>2$ ). According to the ICC (range T1: 3-9 \% and T2: 4-13\%) and the design effect (range T1: 1.35-2.00 and range T2: 1.43-2.48) statistics, although the school-level variance in perceived consistency

\footnotetext{
${ }^{1}$ One of the items on the original scale was missing at Time 1 for technical reasons. The factor structure and reliability of the scale was sufficient.
} 
of the intended direction exceeded 10 per cent at $\mathrm{T} 2$, the school-level variance was rather small on most of the scales (Table 1). Thus, the person-centred analysis was considered reasonable.

Table 1. Correlations, Cronbach's alphas, means, and standard deviations among the scales.

\begin{tabular}{lcccccccc}
\hline & 1. & 2. & 3. & 4. & 5. & 6. & 7. & 8. \\
\hline 1. T1: CON & - & & & & & & & \\
2. T1: INT & .64 & - & & & & & & \\
3. T1: ALI & .72 & .69 & - & & & & & \\
4. T1: SCI & .66 & .62 & .60 & - & & & & \\
5. T2: CON & .71 & .50 & .55 & .52 & - & & & \\
6. T2: INT & .52 & .65 & .53 & .48 & .64 & - & & \\
7. T2: ALI & .58 & .53 & .65 & .49 & .73 & .70 & - & \\
8. T2: SCI & .56 & .48 & .47 & .62 & .67 & .62 & .61 & - \\
Number of items & 6 & 4 & 6 & 6 & 6 & 4 & 7 & 6 \\
$\alpha$ & .87 & .74 & .84 & .90 & .89 & .77 & .88 & .91 \\
$M$ & 3.90 & 5.02 & 4.46 & 4.46 & 3.76 & 4.79 & 4.35 & 4.28 \\
SD & 1.00 & .85 & .81 & .96 & 1.03 & .90 & .84 & .99 \\
Min & 1.00 & 1.75 & 1.33 & 1.00 & 1.00 & 1.00 & 1.00 & 1.00 \\
Max & 7.00 & 7.00 & 6.67 & 7.00 & 6.50 & 6.75 & 6.43 & 7.00 \\
ICC & .09 & .03 & .03 & .07 & .13 & .04 & .06 & .08 \\
Design effect & 2.00 & 1.35 & 1.37 & 1.76 & 2.48 & 1.43 & 1.70 & 1.93
\end{tabular}

$\overline{\mathrm{CON}}=$ Consistency of the intended direction; INT = Integrative approach to teaching and learning; ALI $=$ Alignment between objectives, content and assessment; SCI $=$ School impact. All correlations are significant at $p<0.01$.

Mean scores for each scale at both time points were calculated. Table 1 presents the correlations, Cronbach's Alphas, sample means, standard deviations, and minimum and maximum values among the scales at the two time points. The means, which are rather close to the scale midpoint, show that the comprehensive school teachers had rather mixed perceptions of the core curriculum's coherence and the reform's impact on further school development. At both Time 1 and Time 2, the highest mean scores among the components of curriculum coherence were on the integrative approach to teaching and learning scale, whereas the lowest mean was on the consistency of the intended direction scale. The correlations between the scales were high and statistically significant $(p<.01)$ in the expected direction. The strongest correlations occurred between scales within time, and within scales between the time points. 


\subsection{Analysis}

A latent profile analysis was conducted using Mplus version 7.4 to examine individual variation in teachers' perceptions and their development (Muthén \& Muthén, 1998-2015). The mean variables of the three curriculum coherence subscales at both time points were used as latent class indicators. The residual variances of each subscale were allowed to correlate between the two time points to model the repeated measurements. The within-class variances were constrained equal across classes. The analysis was conducted to estimate $1-$ 7 class solutions, and the number of latent profiles was decided based on the Akaike information criterion (AIC), the Bayesian information criterion (BIC), adjusted BIC (aBIC) information-criteria-based indices, and the Vuong-Lo-Mendell-Rubin likelihood ratio test (VLMR), the Lo-Mendell-Rubin Adjusted LRT (aLRT), and the Bootstrap Likelihood Ratio Test (BLRT) (Berlin, Williams, \& Parra, 2014; Nylund, Asparouhov, \& Muthén, 2007). In addition, the entropy statistics and average latent class probabilities were examined to evaluate the clarity of the different solutions.

The information-criteria-based indices showed decreasing values until the sevenclass solution, hence the lowest values were not reached (Table 2). In addition, the BLRT showed an improving fit with each additional class. The VLMR and aLRT likelihood ratio tests indicated that the two-class model was better than the one-class model, and the threeclass model also showed an improving fit from the two-class solution. The addition of the fourth class did not improve the fit, whereas the fifth class again provided a better solution compared to the four-class model. Neither the sixth not the seventh class improved the model fit from the previous models. Thus, the five-class model was chosen as the best one in light of the VLMR and aLRT likelihood ratio tests (Berlin, Williams, \& Parra, 2014). The class sizes in the five-class solution were also adequate and showed sufficient separation between classes according to the entropy value and the average latent class probabilities. 
Table 2. The latent profile solutions in classes 1-7.

\begin{tabular}{|c|c|c|c|c|c|c|c|c|c|c|}
\hline $\begin{array}{l}\text { No. } \\
\text { classes }\end{array}$ & $\log L(n f)$ & AIC & $\mathrm{BIC}$ & $\mathrm{aBIC}$ & Entropy & $\begin{array}{l}\text { Latent class } \\
\text { probabilities }\end{array}$ & VLMR & aLRT & BLRT & Class counts $^{\mathrm{a}}$ \\
\hline 1 & $\begin{array}{l}-6287.90 \\
(15)\end{array}$ & 12605.80 & 12677.85 & 12630.21 & N/A & 1.000 & N/A & N/A & N/A & 901 \\
\hline 2 & $\begin{array}{l}-5847.92 \\
(22)\end{array}$ & 11739.83 & 11845.51 & 11775.64 & .78 & $0.93,0.94$ & .00 & .00 & .00 & $\begin{array}{l}333,568 \\
(324,577)\end{array}$ \\
\hline 3 & $\begin{array}{l}-5624.83 \\
(29)\end{array}$ & 11307.66 & 11446.96 & 11354.86 & .81 & $\begin{array}{l}0.91,0.91, \\
0.91\end{array}$ & .01 & .01 & .00 & $\begin{array}{l}175,487,239 \\
(173,495, \\
233)\end{array}$ \\
\hline 4 & $\begin{array}{l}-5527.77 \\
(36)\end{array}$ & 11127.54 & 11300.47 & 11186.14 & .84 & $\begin{array}{l}0.95,0.90 \\
0.91,0.91\end{array}$ & .09 & .10 & .00 & $\begin{array}{l}30,227,444, \\
200(29,225, \\
448,197)\end{array}$ \\
\hline 5 & $\begin{array}{l}-5446.70 \\
(43)\end{array}$ & 10979.40 & 11185.95 & 11049.39 & .82 & $\begin{array}{l}0.98,0.89 \\
0.86,0.83 \\
0.91\end{array}$ & .03 & .03 & .00 & $\begin{array}{l}24,429,82 \\
177,189(23, \\
437,83,172, \\
186)\end{array}$ \\
\hline 6 & $\begin{array}{l}-5378.84 \\
(50)\end{array}$ & 10857.67 & 11097.85 & 10939.06 & .78 & $\begin{array}{l}0.95,0.89 \\
0.84,0.82 \\
0.89,0.78\end{array}$ & .16 & .17 & .00 & $\begin{array}{l}25,87,183, \\
310,152,144 \\
(24,87,179, \\
322,149,140)\end{array}$ \\
\hline 7 & $\begin{array}{l}-5326.44 \\
(57)\end{array}$ & 10766.89 & 11040.68 & 10859.66 & .80 & $\begin{array}{l}0.98,0.83, \\
0.87,0.79, \\
0.94,0.82, \\
0.90\end{array}$ & .10 & .11 & .000 & $\begin{array}{l}24,171,86, \\
134,13,317, \\
156(22,166, \\
87,127,12, \\
334,153)\end{array}$ \\
\hline
\end{tabular}

$\overline{\log \mathrm{L}}=\log$ likelihood value; $\mathrm{nf}=$ number of free parameters; $\mathrm{AIC}=$ Akaike information criterion; $\mathrm{BIC}=$ Bayesian information criterion; $\mathrm{aBIC}=$ adjusted Bayesian information criterion; VLMR $=$ Vuong-Lo-MendellRubin likelihood ratio test; aLRT $=$ Lo-Mendell-Rubin adjusted likelihood ratio test; BLRT $=$ bootstrapped likelihood ratio test. The selected model is in boldface.

${ }^{a}$ Class counts based on estimated posterior probabilities and the classification of individuals based on their most likely latent class membership (in parenthesis).

To test the equality of the means in the perceived school impact across the latent classes, school impact mean scores at Times 1 and 2 were added as auxiliary variables in the latent profile analysis using the BCH setting in Mplus (Muthén \& Muthén, 1998-2015). The BCH method is recommended for distal outcome models that evaluate the means across classes for a continuous auxiliary variable (Asparouhov \& Muthén, 2014; Muthén \& Muthén, 19982015). By analyzing the association between the latent class variable and the auxiliary variables using the $\mathrm{BCH}$ method, the latent class formation is not affected by the auxiliary variables and the misclassification in the latent class variable is taken into account (Asparouhov \& Muthén, 2014). 


\section{Results}

\subsection{Curriculum coherence profiles}

Five coherence profiles were identified (Figure 1): 1) high coherence; 2) high-moderate coherence; 3) low-moderate coherence; 4) decreasing coherence; and 5) low coherence. The high coherence profile represented 21 percent of the sample and manifested rather high perceptions of curriculum coherence in all three components at both time points. The highmoderate coherence profile represented almost half of the sample (47.6\%), with high perceptions of the integrative approach to teaching and learning and slightly above average perceived alignment, whereas they did not agree or disagree with the consistency of the intended direction of the curriculum. Teachers in the low-moderate coherence profile (19.7\%) perceived the consistency of the intended direction to be slightly lower than both the integrative approach to teaching and learning and alignment between objectives, content and assessment, with which they did not strongly agree or disagree. The decreasing coherence profile accounted for 9.1 percent of the sample, and was characterized by moderate levels of perceived curriculum coherence at Time 1 and low perceived curriculum coherence at Time 2. Finally, the low coherence profile (2.7\%) perceived all the curriculum coherence components as below average at both time points. The mean differences between the profiles were statistically significant, the exceptions being between the Decreasing coherence and Low coherence profiles at $\mathrm{T} 2$, and between the Low-moderate coherence and Decreasing coherence profiles at T1 regarding the consistency of the intended direction and the integrative approach to teaching and learning. 


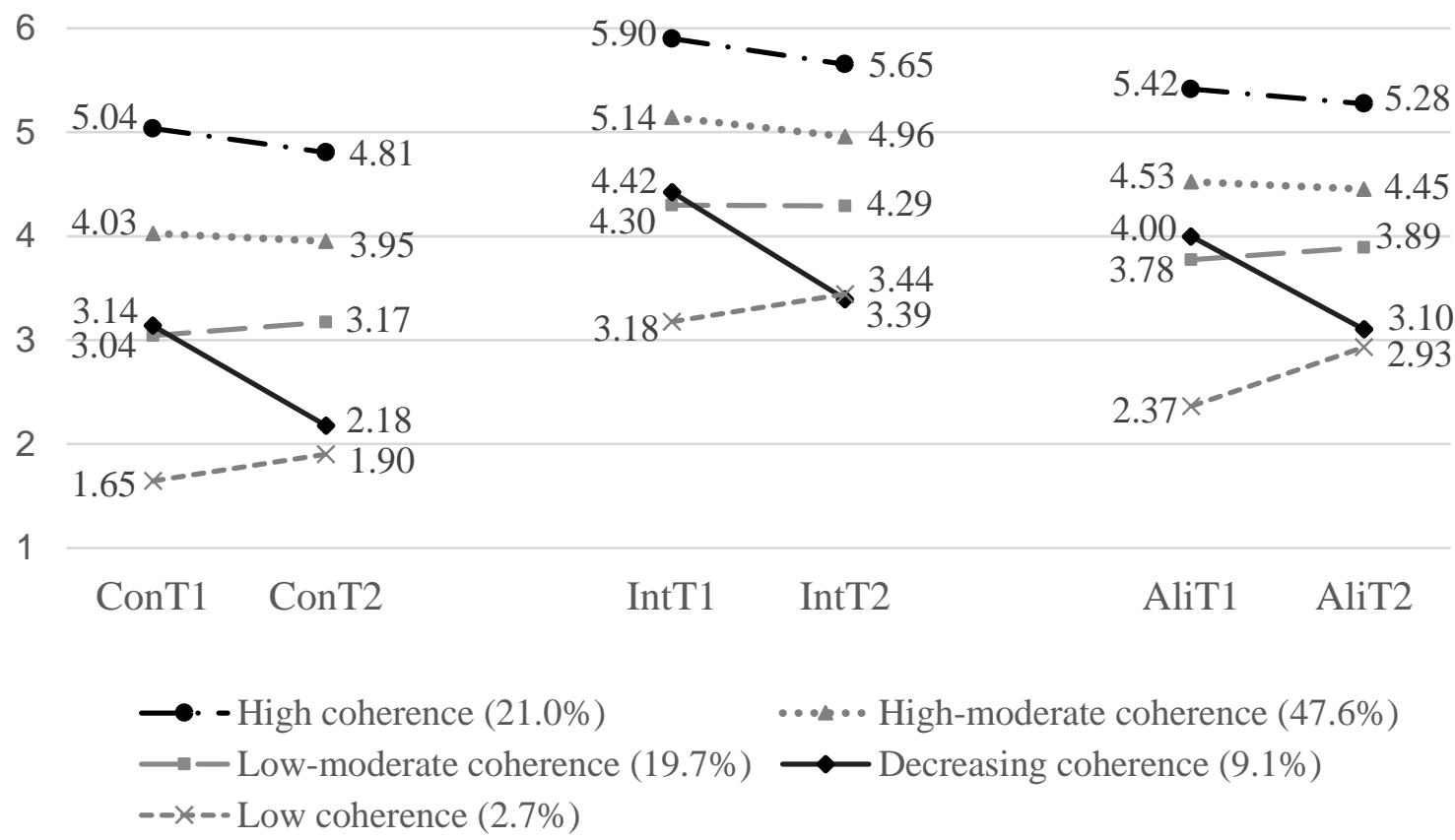

Figure 1. Profiles of perceived curriculum coherence in terms of the consistency of the intended direction $(\mathrm{CON})$, the integrative approach to teaching and learning (INT), and alignment between objectives, content and assessment (ALI) at two time points.

The development of the teachers' perceptions over the two time points was further examined with paired-samples t-tests using the most likely class membership as a grouping variable. Slight statistically significant decrease in perceived curriculum coherence in terms of all three coherence components was detected in the two profiles with the highest perceived curriculum coherence, i.e. high coherence $(\mathrm{CON}: t(185)=4.27, p<.001, d=0.31$; INT: $t(185)=4.86$, $p<.001, d=0.36$; ALI: $t(185)=2.88, p<.01, d=0.21)$ and high-moderate coherence $(\mathrm{CON}$ : $t(430)=2.26, p<.05, d=0.11$; INT: $t(435)=6.09, p<.001, d=0.29$; ALI: $t(429)=2.49, p$ $<.05, d=0.12$ ) during the one-year follow-up in the early stages of the curriculum implementation. In turn, teachers in the low coherence profile gained slightly higher perceptions of the consistency of the intended direction (CON: $t(22)=-2.69, p<.05, d=$ 0.56 ) and alignment within the curriculum (ALI: $t(22)=-3.50, p<.01, d=0.73$ ) between the measurements. In the low-moderate coherence profile a statistically significant increase was also detected in these two components of curriculum coherence $(\mathrm{CON}: t(171)=-2.89, p<$ $.01, d=0.22$; ALI: $t(171)=-3.36, p<.01, d=0.26)$. The decreasing coherence profile showed the greatest change in perceived curriculum coherence, with a statistically significant decrease in all the components $(\mathrm{CON}: t(81)=11.46, p<.001, d=1.27$; INT: $t(82)=12.14$, $p<.001, d=1.33$; ALI: $t(82)=11.76, p<.001, d=1.29)$. 


\subsection{Differences in perceived school impact}

The results showed that the perceived school impact of the curriculum reform, i.e. whether the curriculum development process was perceived as maintaining active development work in schools, committing teachers to the development work, and directing the development work towards resolving problems faced in schools, varied significantly among the five curriculum coherence profiles (Table 3). Teachers in the high coherence profile estimated the school impact highest at both time points, whereas the low coherence profile perceived the lowest potential school impact at Time 1, and among the lowest at Time 2. Teachers in the high-moderate coherence profile also had stronger perceptions about the impact of the reform on school-level development than the low-moderate coherence and decreasing coherence profiles at both time points. The Decreasing coherence profile did not differ from the low-moderate coherence profile in perceived school impact at Time 1, but had lower perceptions of school impact at Time 2. Furthermore, the decreasing coherence profile did not differ from the low coherence group in the perceived reform's impact on school level development at Time 2. Thus, it seems that the more coherent the core curriculum is perceived to be, the stronger are the perceptions of the school-level impact of the reform work.

Table 3. School impact means, standard errors, and Chi-square values for the tests of equality of means across the profiles at Times 1 and 2.

\begin{tabular}{llllll}
\hline Profiles & $\begin{array}{l}\text { 1. High } \\
\text { coherence }\end{array}$ & $\begin{array}{l}\text { 2. High- } \\
\text { moderate } \\
\text { coherence }\end{array}$ & $\begin{array}{l}\text { 3. Low- } \\
\text { moderate } \\
\text { coherence }\end{array}$ & $\begin{array}{l}\text { 4. Decreasing } \\
\text { coherence }\end{array}$ & $\begin{array}{l}\text { 5. Low } \\
\text { coherence }\end{array}$ \\
\hline T1: School impact & & & & & \\
\hline$M$ & 5.42 & 4.58 & 3.75 & 3.76 & 2.53 \\
$S E$ & .06 & .04 & .07 & .11 & .21 \\
1. & - & & & & \\
2. & 116.79 & - & & & \\
3. & 334.43 & 95.74 & - & - & - \\
4. & 181.64 & 51.82 & $0.00^{\text {ns }}$ & 26.60 & - \\
5. & 171.80 & 90.40 & 29.41 & &
\end{tabular}

\begin{tabular}{llllll}
\hline \multicolumn{1}{l}{ T2: School impact } & \multicolumn{5}{l}{} \\
\hline$M$ & 5.26 & 4.40 & 3.83 & 2.82 & 2.81 \\
$S E$ & .06 & .04 & .06 & .13 & .26 \\
1. & - & & & \\
2. & 136.00 & - & & & \\
3. & 288.04 & 50.64 & - & - & - \\
4. & 303.37 & 138.39 & 43.76 & $0.00^{\mathrm{ns}}$ & - \\
5. & 82.36 & 35.50 & 13.68 &
\end{tabular}




\section{Methodological reflection and limitations}

The five-class solution of the latent profile analysis was considered as the best model according to the VLMR and the aLRT likelihood ratio tests, yet the information-criteriabased indices did not reach the lowest values. Nevertheless, the five profiles were reasonable in terms of content, and showed sufficient separation between classes while having adequate class sizes. Further studies are needed that examine the patterns of teachers' perceived curriculum coherence to see whether similar or different profiles can be detected in other contexts. The residual covariances between the two measurements of each scale were utilized to take into account the longitudinal design. However, it would also be useful to examine the development of teachers' perceived curriculum coherence with other longitudinal analyses such as latent growth modeling, which requires at least three measurements. Moreover, the person-centered approach does not allow causal inference about the associations with other variables. Additional research and longitudinal analysis are needed to allow further examination of the development of teachers' perceptions and the relationship between perceived curriculum coherence and the school-level impact of the reform.

The participants of this study included teachers who responded to the survey at both time points, and therefore do not represent all the teachers from the case schools. Some of the attrition was due to unidentifiable responses, retirement or the movement of teachers to work outside the case schools. It is also possible that some teachers left the profession, and the sample may not represent their perceptions. It is also important to note that the teachers' self-reported perceptions of the impact of the reform on schools do not necessarily reflect real changes in classroom practice. Nevertheless, the perceived school impact may reflect some of the attitudes, beliefs or intentions of teachers in terms of how, in practice, the reform will influence school-level practices and the continuing school development work. More research is needed to examine the relationship between teachers' perceptions of curriculum coherence and changes in their beliefs about teaching and learning, as well as their classroom practice.

\section{Discussion}

In this study, we explored individual variation among Finnish comprehensive school teachers' perceptions of the recently reformed core curriculum document's coherence. The development of these perceptions was examined over a one-year follow-up during the early stages of the implementation of the new curriculum. Five distinctive coherence profiles were identified, which remained somewhat stable over the follow-up. The two largest profile groups showed rather high levels of perceived curriculum coherence, and only a minority of the teachers belonged to the low coherence group. Accordingly, most of the respondents perceived the core curriculum to be quite coherent in terms of all three components, including 
consistency of the intended direction, an integrative approach to teaching and learning, and alignment between objectives, content and assessment.

The hierarchy of the three components of curriculum coherence remained the same within each profile group. Out of the three components of curriculum coherence, an integrative approach to teaching and learning, was agreed upon most extensively across the different profiles at both time points. Accordingly, regardless of the profile, most teachers seemed to share an understanding of the core values for teaching and learning, including the idea that the new core curriculum aims to harmonize teaching and to encourage teachers to use activating and engaging teaching methods and assessment that supports learning. There was less agreement across the five profiles on the other two coherence components, i.e. alignment between objectives, content and assessment, and consistency of the intended direction. For instance, the high coherence group perceived the core curriculum as being well aligned, whereas the low coherence and the decreasing coherence profile at Time 2 disagreed on the alignment within the core curriculum. The teachers differed even more in terms of how they perceived the consistency of the intended direction. Hence, there was less agreement among them on whether the new core curriculum has a consistent direction that clarifies and delimits the work of schools and teachers, and supports the teaching of essential material. This may imply that the differences in teachers' coherent understandings about the core curriculum arise from the broader intended direction of the curriculum. It could also imply that building coherence in terms of the intended direction may be more challenging for teachers than constructing a coherent understanding of the integrative approach to teaching and learning and alignment between the curriculum's objectives, content and assessment, which might be more easily developed during everyday classroom work.

Further investigation showed that slight changes in teachers' perceptions of curriculum coherence occurred during the first year of its implemention in schools. Although the overall trend seemed to be a slight decrease, the person-centered approach showed that different patterns emerged in teachers' perceptions of the core curriculum's coherence in the one-year follow-up. The two profiles with the highest perceived curriculum coherence at the first measurement, high and high-moderate coherence, showed a slight decrease after the first year of implementing the curriculum in schools. In turn, the low and low-moderate coherence profiles slightly increased their perceptions of the core curriculum's coherence. Teachers in the decreasing coherence profile showed the biggest drop in the perceptions of curriculum coherence compared to the other profiles. These changes may reflect the fact that teachers develop their perceptions when they start to experiment with the curriculum in practice - that success or failure in transforming the new curriculum into everyday classroom practice interacts with teachers' understandings and beliefs about the curriculum and its potential effects (see Bliss \& Wanless, 2018; Spillane et al., 2002; Fullan, 2007). It could be assumed that experimentation in the classroom constitutes an ecologically relevant test of coherence building that could result in experiencing the incongruities and contradictions, or in strengthening coherence by developing the curriculum through practice. Accordingly, the 
slight decreases in the high coherence profiles could be attributable to identifying or experiencing some challenges related to the implementation of the curriculum in everyday classroom practice, whereas the slight increase in the low coherence profiles may have resulted from starting to gain more coherent perceptions of the curriculum after developing it in the classroom practice. Those in the decreasing coherence profile, in turn, may have identified or experienced challenges during the classroom implementation in addition to initially perceiving the curriculum as not very coherent.

We also examined the association between the profiles and the perceived impact of the reform on schools, i.e. perceptions of how the reform work sustains active development work in schools and the commitment of teachers to it. Teachers' perceptions of the impact of the reform on school-level development varied significantly across the curriculum coherence profiles. Those belonging to the higher coherence profiles were more optimistic about the impact of the reform (see also Sullanmaa et al., 2019a). These results imply an association between teachers' perceptions of curriculum coherence and their expectations of the reform's impact on school-level development. Teachers' beliefs about the potential benefits of the reform work as well as their experiences of transforming the curriculum into classroom practice are likely to play a central role in coherence building (see Fullan, 2007; Spillane et al., 2002). Hence, teachers' processes of interpreting the curriculum and constructing understanding of the reform's potential effects on the school level should be simultaneously supported, for instance, by providing resources and support to engage in collaborative negotiations concerning the meaning of the reformed curriculum and its effects in schools.

It has been previously suggested that teachers' understandings of and commitment in curriculum reform is crucial (e.g. Fullan, 2007; Ketelaar et al., 2012). This study contributes to this understanding by showing that teachers' understandings of the curriculum as a coherent whole seem to vary, and seem to facilitate their interpretations of the reform's potential effects and benefits on the school level practice. The five distinctive profiles imply that coherence is a dynamic and interactive process that develops in interaction with the context (see also Honig \& Hatch, 2004), rather than a permanent quality of the curriculum document. The hierarchical arrangement of the components of curriculum coherence within the profiles may imply that teachers construct coherence in different ways, starting from the core issues of teaching and learning, making sense of what the new core curriculum means for the development of the core of teachers' work, as well as interpreting the core curriculum in terms of objectives, content and assessment and constructing alignment within these elements.

The findings further imply that sustaining and cultivating a sense of coherence among teachers' perceptions requires constant effort throughout the reform process and even afterwards (see Fullan, 2007). The individual variation in teachers' perceptions and the developmental trajectories imply that teachers may need different types of support in coherence building, and that this need may vary during the course of the reform work. What happens during the initial phases of curriculum implementation in classroom practice 
influences teachers' perceptions of the curriculum and the reform in different ways (see Coburn, 2004). Some might perceive challenges and contradictions in the curriculum, whereas others might arrive at a coherent understanding by putting their ideas into practice. Accordingly, different kinds of strategies may be needed to facilitate individual and shared sense-making over the curriculum. For instance, acknowledging and building structural connections and continuity among objectives, content and assessment on the subject or classroom level could foster perceived alignment, whereas perceiving consistency in the intended direction might require collective discussion and negotiation on more abstract issues related to the curriculum's direction and aims, which might take more time. In sum, the results suggest that coherence building in the form of individual and shared sense-making should be ingrained in any curriculum reform. 


\section{References}

Allen, C. D. \& Penuel, W. R. (2015). Studying teachers' sensemaking to investigate teachers' responses to professional development focused on new standards. Journal of Teacher Education, 66(2), 136-149. doi: 10.1177/0022487114560646

Asparouhov, T., \& Muthén, B. (2014). Auxiliary Variables in Mixture Modeling: Using the BCH Method in Mplus to Estimate a Distal Outcome Model and an Arbitrary Secondary Model. Mplus Web Notes, 21, Version 2. Retrieved on 09.09.2018 from: https://www.statmodel.com/examples/webnotes/webnote21.pdf

Beane, J. A. (1995). Toward a coherent curriculum. Alexandria, VA: ASCD.

Berlin, K. S., Williams, N. A., \& Parra, G. R. (2014). An introduction to latent variable mixture modeling (part 1): Overview and cross-sectional latent class and latent profile analyses. Journal of Pediatric Psychology, 39(2), 174-187. doi: 10.1093/jpepsy/jst084

Bliss, C.M. \& Wanless, S.B. (2018). Development and initial investigation of a self-report measure of teachers' readiness to implement. Journal of Educational Change, 19(2), 269-291. doi: 10.1007/s10833-018-9324-5

Boesen, J., Helenius, O., Bergqvist, E., Bergqvist, T., Lithner, J., Palm, T., \& Palmberg, B. (2014). Developing mathematical competence: From the intended to the enacted curriculum. The Journal of Mathematical Behavior, 33, 72-87. doi:

10.1016/j.jmathb.2013.10.001

Coburn, C. E. (2003). Rethinking scale: Moving beyond numbers to deep and lasting change. Educational Researcher, 32(6), 3-12. doi: 10.3102/0013189X032006003

Coburn, C. E. (2004). Beyond Decoupling: Rethinking the Relationship Between the Institutional Environment and the Classroom. Sociology of Education, 77(3), 211-244. doi: $10.1177 / 003804070407700302$

Cohen, D. K., \& Hill, H. C. (2000). Instructional policy and classroom performance. Teachers College Record, 102(2), 294-343

Darling-Hammond, L. (1998). Policy and change: Getting beyond bureaucracy. In A. Hargreaves, A. Lieberman, M. Fullan \& D. Hopkins (Eds.), International handbook of educational change (pp. 642-667). Dordrecht: Kluwer Academic. doi:10.1007/1-40204453-4_18

Darling-Hammond, L., \& McLaughlin, M. W. (1995). Policies that support professional development in an era of reform. Phi Delta Kappan, 76(8), 597-604.

Day, C., Sammons, P., Stobart, G., Kington, A., \& Gu, Q. (2007). Teachers Matter: Connecting work, lives and effectiveness. Maidenhead: McGraw-Hill Education.

Donnell, L. A., \& Gettinger, M. (2015). Elementary school teachers' acceptability of school reform: Contribution of belief congruence, self-efficacy, and professional development. Teaching and Teacher Education, 51, 47-57. doi:

10.1016/j.tate.2015.06.003 
Drake, S. M., \& Miller, J. P. (2001). Teachers' perceptions of their roles: Life in and beyond the classroom. Curriculum and Teaching, 16(1), 5-23. doi: 10.7459/ct/16.1.02

Fernandez, T., Ritchie, G., \& Barker, M. (2008). A sociocultural analysis of mandated curriculum change: The implementation of a new senior physics curriculum in New Zealand schools. Journal of Curriculum Studies, 40(2), 187-213.

FNBE [Finnish National Board of Education] (2014). National core curriculum for basic education. Retrieved on 09.09.2018 from http://www.oph.fi/download/163777_perusopetuksen_opetussuunnitelman_perusteet_ 2014.pdf

Fortus, D., Sutherland Adams, L. M., Krajcik, J., \& Reiser, B. (2015). Assessing the role of curriculum coherence in student learning about energy. Journal of Research in Science Teaching, 52(10), 1408-1425.

Fullan, M. (1996). Turning systemic thinking on its head. Phi Delta Kappan, 77(6), 420423.

Fullan, M. (2007). The new meaning of educational change (4th ed.). New York: Teachers College Press.

Gawlik, M. A. (2015). Shared sense-making: How charter school leaders ascribe meaning to accountability. Journal of Educational Administration, 53(3), 393-415. doi:10.1108/JEA-08-2013-0092

Geijsel, F., Sleegers, P., van den Berg, R., \& Kelchtermans, G. (2001). Conditions fostering the implementation of large-scale innovation programs in schools: Teachers' perspectives. Educational Administration Quarterly, 37(1), 130-166. doi:10.1177/00131610121969262

Geraedts, C., Boersma, K. T., \& Eijkelhof, H. M. C. (2006). Towards coherent science and technology education. Journal of Curriculum Studies, 38(3), 307-325. doi: 10.1080/00220270500391589

Honig, M. I., \& Hatch, T. C. (2004). Crafting coherence: How schools strategically manage multiple, external demands. Educational Researcher, 33(8), 16-30. doi: 10.3102/0013189X033008016

Ketelaar, E., Beijaard, D., Boshuizen, H. P. A., \& Den Brok, P. J. (2012). Teachers' positioning towards an educational innovation in the light of ownership, sense-making and agency. Teaching and Teacher Education, 28(2), 273-282. doi:

10.1016/j.tate.2011.10.004

Kumpulainen, K., \& Lankinen, T. (2016). Striving for educational equity and excellence: Evaluation and assessment in finnish basic education. In H. Niemi, A. Toom \& A. Kallioniemi (Eds.), Miracle of education (pp. 69-81). Rotterdam: SensePublishers. doi: 10.1007/978-94-6091-811-7_5

Lasky, S. (2005). A sociocultural approach to understanding teacher identity, agency and professional vulnerability in a context of secondary school reform. Teaching and Teacher Education, 21(8), 899-916. doi: 10.1016/j.tate.2005.06.003 
Lee, J. C. (2000). Teacher receptivity to curriculum change in the implementation stage: The case of environmental education in Hong Kong. Journal of Curriculum Studies, 32(1), 95-115. doi:10.1080/002202700182871

Martone, A., \& Sireci, S. G. (2009). Evaluating alignment between curriculum, assessment, and instruction. Review of Educational Research, 79(4), 1332-1361. doi: $10.3102 / 0034654309341375$

Mølstad, C. E. (2015). State-based curriculum-making: approaches to local curriculum work in Norway and Finland. Journal of Curriculum Studies, 47(4), 441-461, doi: 10.1080/00220272.2015.1039067

Muthén, L., \& Muthén, B. O. (1998-2015). Mplus users guide (6th ed.). Los Angeles: Muthen \& Muthen.

März, V., \& Kelchtermans, G. (2013). Sense-making and structure in teachers' reception of educational reform. A case study on statistics in the mathematics curriculum. Teaching and Teacher Education, 29, 13-24. doi:10.1016/j.tate.2012.08.004

Newmann, F. M., Smith, B., Allensworth, E., \& Bryk, A. S. (2001). Instructional program coherence: What it is and why should it guide school improvement policy. Educational Evaluation and Policy Analysis, 23(4), 297-321. doi: 10.3102/01623737023004297

$\mathrm{Ng}$, S. W. (2009). Why did principals and teachers respond differently to curriculum reform? Teacher Development, 13(3), 187-203. doi:10.1080/13664530903335558

Nylund, K. L., Asparouhov, T., \& Muthén, B. O. (2007). Deciding on the Number of Classes in Latent Class Analysis and Growth Mixture Modeling: A Monte Carlo Simulation Study. Structural Equation Modeling: A Multidisciplinary Journal, 14(4), 535-569, doi: 10.1080/10705510701575396

Penuel, W. R., \& Fishman, B. J., Gallagher, L. P., Korbak, C., \& Prado-Lopez, B. (2008). The mediating role of coherence in curriculum implementation. Proceedings of the Biennial International Conference of the Learning Sciences (ICLS). Utrecht, The Netherlands: International Society of the Learning Sciences, Inc.

Pietarinen, J., Pyhältö, K., \& Soini, T. (2017). Large-scale curriculum reform in Finland exploring the interrelation between implementation strategy, the function of the reform, and curriculum coherence. The Curriculum Journal, 28(1), 22-40. doi:10.1080/09585176.2016.1179205

Priestley, M., Minty, S., \& Eager, M. (2014). School-based curriculum development in Scotland: curriculum policy and enactment. Pedagogy, Culture \& Society, 22(2), 189211. doi: $10.1080 / 14681366.2013 .812137$

Pyhältö, K., Pietarinen, J., \& Soini, T. (2012). Do comprehensive school teachers perceive themselves as active professional agents in school reforms? Journal of Educational Change, 13 (1), 95-116. doi:10.1007/s10833-011-9171-0

Pyhältö, K., Pietarinen, J., \& Soini, T. (2018). Dynamic and shared sense-making in largescale curriculum reform in school districts. The Curriculum Journal, 29(2), 181-200. doi: 10.1080/09585176.2018.1447306 
Ramberg, M. R. (2014). What makes reform work? - School-based conditions as predictors of teachers' changing practice after a national curriculum reform. International Education Studies, 7(6), 46-65. doi:10.5539/ies.v7n6p46

Robinson, S. (2012). Constructing teacher agency in response to the constraints of education policy: Adoption and adaptation. Curriculum Journal, 23(2), 231-245. doi:10.1080/09585176.2012.678702

Russell, J. L., \& Bray, L. E. (2013). Crafting coherence from complex policy messages: educators' perceptions of special education and standards-based accountability policies. Education Policy Analysis Archives, 21(12). Retrieved on 09.09.2018 from http://epaa.asu.edu/ojs/article/view/1044.

Sahlberg, P. (2015). Finnish lessons 2.0: What can the world learn from educational change in Finland? (2nd ed.). New York: Teachers College Press.

Schmidt, W. H., Wang, H. C., \& McKnight, C. C. (2005). Curriculum coherence: An examination of US mathematics and science content standards from an international perspective. Journal of Curriculum Studies, 37(5), 525-559. doi: 10.1080/0022027042000294682

Smith, M., \& O'Day, J. A. (1991). Systemic school reform. In S. H. Fuhrman \& B. Malen (Eds.), The politics of curriculum and testing (pp. 233-268). Bristol, PA: Falmer.

Smith, L. K., \& Southerland, S. A. (2007). Reforming practice or modifying reforms?: Elementary teachers' response to the tools of reform. Journal of Research in Science Teaching, 44(3), 396-423. doi: 10.1002/tea.20165

Snijders, T. A. \& Bosker, R. J. (2012). Multilevel analysis: An introduction to basic and advanced multilevel modeling (2nd ed.). Thousand Oaks, CA: Sage Publications.

Southerland, S., Sowell, S., Blanchard, M., \& Granger, E. (2011). Exploring the construct of pedagogical discontentment: A tool to understand science teachers' openness to reform. Research in Science Education, 41(3), 299-317. doi:10.1007/s11165-0109166-5

Spillane, J. P., Reiser, B. J., \& Reimer, T. (2002). Policy implementation and cognition: Reframing and refocusing implementation research. Review of Educational Research, 72(3), 387-431. doi:10.3102/00346543072003387

Squires, D. A. (2009). Curriculum alignment: Research-based strategies for increasing student achievement. Thousand Oaks: Corwin Press.

Sullanmaa, J., Pyhältö, K., Pietarinen, J. \& Soini, T. (2019a). Curriculum coherence as perceived by district-level stakeholders in large-scale national curriculum reform in Finland. The Curriculum Journal, 30(3), 244-263. doi: 10.1080/09585176.2019.1607512

Sullanmaa, J., Pyhältö, K., Pietarinen, J. \& Soini, T. (2019b). Differences in state- and district-level stakeholders' perceptions of curriculum coherence and school impact in national curriculum reform. Journal of Educational Administration, 57(3), 210-226. doi: 10.1108/JEA-08-2018-0153 
Tan, Y. S. M., \& Nashon, S. M. (2015). Promoting teachers' collaborative exploration of a new science curriculum: the case of a Singapore learning study. Professional Development in Education, 41(4), 671-689. doi: 10.1080/19415257.2014.944670

Waugh, R. and Godfrey, J. (1993). Teacher receptivity to system-wide change in the implementation stage. British Educational Research Journal, 19(5), 565-578. doi:10.1080/0141192930190509

Webb, N. L. (1997). Determining alignment of expectations and assessments in mathematics and science education. NISE Brief, 2(1). National Institute for Science Education.

Vitikka, E., Krokfors, L., \& Hurmerinta, E. (2016). The finnish national core curriculum. In H. Niemi, A. Toom \& A. Kallioniemi (Eds.), Miracle of education (pp. 83-96). Rotterdam: SensePublishers. doi: 10.1007/978-94-6091-811-7_6

Yin, H., Lee, J. C., \& Jin, Y. (2011). Teacher receptivity to curriculum reform and the need for trust: An exploratory study from southwest China. The Asia-Pacific Education Researcher, 20(1), 35-47. 


\section{Appendix 1}

The items of curriculum coherence and school impact scales.

Scales*

Curriculum coherence

\section{Consistency of the intended direction}

(In) the national core curriculum...

Con11: clarifies the entity of a teacher's job

Con12: supports the teaching of the essential material in various subjects

Con13: delimits the duty of the school in a sensible manner

Con14: is clear and well organised

Con15: successfully sums up the most important goals for the operation of the school

Con16: constitutes an aligned foundation for the local curricular work

\section{Integrative approach to teaching and learning}

(In) the national core curriculum...

Int21: encourages teachers to use activating and engaging teaching methods

Int22: encourages teachers to use assessment methods that support learning

Int23: supports the harmonisation of teaching

Int24: the general section creates something new

\section{Alignment between objectives, content and assessments}

(In) the national core curriculum...

Ali31: the goals are in line with the assessment criteria

Ali32 a : a subject constitutes an integral continuum

Ali33: the goals are in line with contents

Ali34: takes a pupil's age range into consideration

Ali35: descriptions of teaching methods in various subjects are in harmony with the general goals

Ali36: constitutes an integral whole

Ali37: the goals of the general section are also well in evidence in the subject section

\section{School impact}

The work to reform the curriculum...

Sci1: maintains active development work at schools

Sci2: commits teachers to working on developing the school

Sci3: helps the school community identify the core tasks

Sci4: directs development work to resolve problems observed in the daily life of the school

Sci5: helps people develop solutions that work at the local level for organizing teaching

Sci6: promotes the resolution of many problems related to basic education at the local level

*Translated from Finnish.

${ }^{a}$ Item Ali32 was missing at Time 1 for technical reasons. 